\title{
Family communication patterns of individuals with and without disabilities
}

\author{
Setareh Shojaee, ${ }^{1}$ Mohammad Saber Khakhaninejad, ${ }^{2}$ Mahmoud Najafi ${ }^{3}$ \\ ${ }^{1}$ Department of Special Education, Faculty of Education and Psychology, Shiraz University, Shiraz; \\ ${ }^{2}$ Department of Foreign Languages and Linguistics, Faculty of Letters and Humanities, Shiraz \\ University, Shiraz; ${ }^{3}$ Faculty of Psychology and Education, University of Semnan, Semnan, Iran
}

\begin{abstract}
The aim of this study was to compare family communication patterns among Iranian individuals with blindness, deafness and individuals with typically developing. The statistical population consisted of all Iranian individuals with blindness, deafness and individuals with typically developing in Shiraz, Iran. The sample consisted of 116 individuals (32 individuals with blindness, 21 individuals with deafness, and 63 individuals with typically developing). The Revised Family Communication Patterns scale was used for measuring the family communication patterns. Multivariate analysis of variance test were used for data analysis. The results showed that conversation orientation in individuals with typically developing were significantly higher than individuals with blindness and deafness $(\mathrm{P}<.001)$. Furthermore, conversation orientation in individuals with blindness was significantly higher than individuals with deafness $(\mathrm{P}<.001)$. Moreover, the findings showed that the conformity orientation in individuals
\end{abstract}

Correspondence: Setareh Shojaee, Department of Special Education, Faculty of Education and Psychology, Shiraz University, Eram Square, Shiraz, Iran.

Tel.: +98.711.6134690 - Fax: +98.711.6286441.

E-mail: bahareman@shirazu.ac.ir

Key words: Family communication patterns, individuals, disabilities.

Acknowledgements: the authors would like to thank the individuals with blindness, deafness and individuals with typically developing in Shiraz participating in this study.

Contributions: SS, provision of research tools, writing methodology and findings, helping to write an introduction and discussion; MSK, provision of research tools, data collection, data analysis and resource gathering, helping to write introduction and discussion; MN, collecting data, collecting resources and helping to write introduction and discussion.

Conflict of interest: the authors declare no potential conflict of interest.

Funding: none.

Received for publication: 19 September 2017.

Revision received: 2 August 2018.

Accepted for publication: 2 August 2018

This work is licensed under a Creative Commons AttributionNonCommercial 4.0 International License (CC BY-NC 4.0).

CCopyright S. Shojaee et al., 2018

Licensee PAGEPress, Italy

Health Psychology Research 2018; 6:7080

doi:10.4081/hpr.2018.7080 with blindness and deafness were significantly higher than individuals with typically developing $(\mathrm{P}<.001)$. It should be noted that there was no significant difference among individuals with blindness and deafness in terms of conformity orientation. The results of the study indicated that reforming of family communication patterns is essential for individuals with blindness and deafness.

\section{Introduction}

The family is the most stable social institution of mankind and has a special role in people's lives (Clark, 2015; Koerner \& Schrodt, 2014). The family has many functions, including these functions can be referred to the family communication patterns. Family communication patterns affect the child's behavior and personality (Rusta, Esfandyari Bayat, \& Ayzinia, 2014). Chaffe, Mcleod, and Wackman (1973) introduced the concept of family communication patterns for the first time. Charoenthaweesub and Hale (2014) believe that family communication patterns are the result of experiences from family interactions. Family communication patterns mean how family members interact with each other, what they say each other, what they do and how they perceive communication with other family members (Koerner \& Maki, 2004).

Family communication patterns contains two dimensions of conversation orientation and conformity orientation (Koerner \& Fitzpatrick, 2002a). Conversation orientation provides a comfort zone for family members, and helps them to participate in various activities. Warm and friendly relations, freedom to express feelings and consult with others are among the features of families with conversation orientation. They tend to value their close relationships, speak to their family members on their private issues, and prevent conflict. They are skillful at maintaining the relationships, and managing the conflicts. They express their opinions openly, and discuss their ideas with everyone, including their parents. Therefore, children are accepted by their family, and their ideas are used in family decision making and dealing with challenges (High \& Scharp, 2015; Koerner \& Fitzpatrick, 2002b).

On the other hand, conformity orientation emphasizes the family members' common attitudes, values and beliefs. Conformity orientation indicates that family relations are based on the common beliefs and attitudes, and avoidance of conflict in family. In these families, when teenagers are more compatible with family circumstances, they are approved by parents, and they would do what their parents want. Individuals in families with conformity orientation have poor relations. Instead of encouraging their interpersonal skills and expressing themselves, they limit themselves to the precise norms and the homogeneous culture. They are often mutually dependent, avoid conflict, and accord to each other (High \& Scharp, 2015; Koerner \& Fitzpatrick, 2002b).

Family communication patterns have a profound impact on 
the quality of life of family members and affect the behavior and performance of each member of the family (Koerner \& Schrodt, 2014). The patterns of communication between family members are important at all stages of life, but more important in adolescence and youth. Because many biological and psychological changes occur in a relatively short period of time during these periods. These changes happen at different rates. That is, adolescents and young individuals must be physically able to participate in activities before they can fully understand the meaning and consequences of such activities. This mismatch between the psychological and biological transition occurs while society and culture have also a significant effect on the lifestyle, attitudes and expectations of the individuals. For this reason, family communication patterns during adolescence and youth is very important and affects the behavior, personality and future life of adolescents and youth (Durdevany, Moin, \& Yahav, 2007; Robinson \& Miller, 2012). Adolescents and youth with disability are not an exception. One of the factors that affect a family communication patterns is having children with disability (Meyer \& Vadasy, 2008). Disability is a part of life in some contemporary families and birth of a child with a disability can challenge all members of the family (Meyer \& Vadasy, 2008).

In this context, there are always some questions in the mind of the experts and psychologists in the field. As examples, how do these families welcome children with disability? How do families of individuals with disability promote the optimal level of quality in the communication? What is the pattern of communications in these families? (Desselle \& Pearlmutter, 1997; Farrell \& Krahn, 2014; Golpich, Darrodi, \& Soleimanyan, 2012).

Research in the literature on families of children with blindness or deafness in Iran has explored the negative impact of having a child with blindness or deafness on parents (Movallali, Abdollahzadeh Rafi, Nemati, 2013; Tavakol, Dehi, Naji, Nasiri, 2008). Some studies have focused on the experiences of Iranian parents of children with blindness or deafness (Behboodi Moghadam, Ghiyasvandian, Shahbazzadegan, \& Shamshiri, 2017; Fathizadeh, et al., 2012), while some research has been conducted on the prevalence of blindness or deafness (Feghhi, Khataminia, Ziaei, \& Latifi, 2009; Hajloo, \& Ansari, 2011; Soori, Javadi, \& Rafati, 2011). Other research about children with blindness or deafness in Iran has focused on the benefits of various educational and interventional methods for children with blindness or deafness (Pourseyyed, Habibollahi, Faramarzi, 2010; Sarabandi, Mobaraki, Chabok, \& Soltani, 2014; Yaghotian, Soliemanian, \& Darrodi, 2015), an examination of specific interventions for parents of children with blindness or deafness (Doostzade, Hemmati Alamdarloo, \& Shojaee, 2017; Khooshab, Jahanbin, Ghadakpour, \& Keshavarzi, 2016), and an overview of causes of blindness and deafness in Iran (Mahdieh, Rabbani, Wiley, Akbari, \& Zeinali, 2010; Ramezani, et al., 2012).

As you can see, no research has yet examined the family communication patterns among Iranian individuals with blindness, deafness and individuals with typically developing. Therefore, there is a gap in the literature regarding how the type of disabilities might impact family communication patterns in Iran. This research seeks to add to the literature about the type of disabilities on the family communication patterns in Iran. The study of the family communication patterns in the life of people with sensory impairment seems necessary due to the importance of these communication in their lives, and also due to the lack of research on the comparison of family communication patterns of individuals with blindness, deafness, and individuals with typically developing in Iran.
For this reason, the aim of the present study was to compare the family communication patterns between Iranian individuals with blindness, deafness and individuals with typically developing. The research questions of the present study included:

Is there a significant difference between the Iranian individuals with blindness, deafness and individuals with typically developing in term of conversation orientation?

Is there a significant difference between the Iranian individuals with blindness, deafness and individuals with typically developing in term of conformity orientation?

\section{Materials and Methods}

This was a survey research. The population consisted of all Iranian individuals with blindness, deafness and individuals with typically developing (13 to 22 years old) in Shiraz, Iran.

\section{Participants and procedure}

The sample consisted of 116 individuals (32 individuals with blindness, 21 individuals with deafness, and 63 individuals with typically developing).

An introduction letter addressing schools and institutions for individuals with blindness and deafness was obtained from the Welfare Organization, Exceptional Education Department and Universities in Shiraz, Iran. All individuals with blindness and deafness in the age range of 13 to 22 years were selected. Therefore, 32 individuals with blindness and 21 individuals with deafness were selected. Furthermore, individuals with typically developing were selected through multistage random sampling. Actually, for selecting the individuals with typically developing, the list of high schools and universities in Shiraz were prepared and randomly 4 high schools for girls, 4 high schools for boys and 1 university were selected. The individuals in the age range of 13 to 22 were asked to participate in the study if they wish. Therefore, 63 individuals with typically developing were selected.

Sample characteristics for individuals with blindness, deafness, and individuals with typically developing are presented in Table 1. There were no significant differences in in the mean age, ratio of boys to girls, birth order, family size, maternal educational level, and family income between the three groups (Table 1).

\section{Instrument: A revised family communication patterns scale}

To assess the family communication patterns, a revised family communication pattern scale was used (Ritchie \& Fitzpatrick, 1990). It is a self-report scale, and contains two subscales of conversation orientation and conformity orientation. It includes 26 items on a five-point Likert scale (from strongly disagree (1) to strongly agree (5)). Fitzpatrick and Ritchie (1994) estimated the reliability for parents and children in three different age groups through three-week interval. It was close to 1 for conversation orientation, and .93 for conformity orientation. Rubin, Rubin, Graham, Perse, and Seibold (2009) reported the Cronbach's alpha coefficient between .84 and .92. It is worth noting that the validity of the instrument was supported (Koerner \& Mary Anne, 2002). Furthermore, there was a strong correlation between the revised family communication pattern scale (Ritchie \& Fitzpatrick, 1990) and relational dimensions inventory (Fitzpatrick, 1988), indicating a good criteria validity of this scale. In this study, the reliability using Cronbach's alpha for the total scale and the subscales of conversation orientation and conformity orientation are $.74, .89$ and .82 , respectively. 


\section{Ethical considerations}

Individuals with blindness, deafness and individuals with typically developing and their parents gave consent for their participation in this study. The participants and parents were aware of the purpose of the study and they had the right to leave the study at any time. They were assured that all their information would remain confidential. The ethical review board of the regional Regular Education Organization, the ethical review board of the regional Special Education Organization, the ethical review board of the regional Welfare Organization and the ethical review board of a shiraz university approved the study.

\section{Results}

Table 2 presents the scores of family communication patterns' subscales in Iranian individuals with blindness, deafness and individuals with typically developing.

As it is evident in Table 1, the mean of conversation orientation in individuals with typically developing is higher than individuals with blindness and deafness. Furthermore, the mean of conversation orientation in individuals with blindness is higher than individuals with deafness. As the Table shows, the means of conformity orientation in individuals with blindness and deafness are high- er than individuals with typically developing. Therefore, multivariate analysis of variance (MANOVA) and Scheffe post hoc tests were used to compare the mean of the mentioned subscales in Iranian individuals with blindness, deafness and individuals with typically developing. The results are presented in Table 3. It is worth noting that before conducting the MANOVA, Levene's test was used to examine the assumptions of homogeneity of variance. This test was not significant for any of the variables. Therefore, MANOVA could be conducted. Furthermore, to study the homogeneity of Covariance Matrices, Box's M Test was used. The result showed that its value was not significant. Therefore, the variance-covariance matrix of the dependent variables are equal in three groups.

According to Table 3, the group effect was significant on the linear combination of dependent variables. Therefore, to investigate the significance of the effect on each dependent variable, MANOVA was used. The results of the MANOVA are presented in Table 4.

As it is evident in Table 4, the results of MANOVA shows that the effects are significant for conversation orientation $[\mathrm{F}=25.44$, $\mathrm{P}<.01]$ and conformity orientation $[\mathrm{F}=6.794, \mathrm{P}<.01]$. Thus, it can be concluded that there is a significant difference between at least a pair of the groups studied in the conversation orientation and conformity orientation. However, it is not clear where the difference exists. So, Scheffe post hoc test was used to investigate the

Table 1. Sample characteristics for individuals with Blindness (B), Deafness (D), and Typical Development (TD).

\begin{tabular}{|c|c|c|c|c|}
\hline & $\begin{array}{l}\text { Individuals with } \mathrm{B} \\
\qquad(\mathrm{n}=32)\end{array}$ & $\begin{array}{l}\text { Individuals with } \mathrm{D} \\
\qquad(\mathrm{n}=21)\end{array}$ & $\begin{array}{l}\text { Individuals with TD } \\
\qquad(\mathrm{n}=63)\end{array}$ & $\begin{array}{c}\text { Total } \\
(\mathrm{N}=116)\end{array}$ \\
\hline Mean age (years) (SD) & $17.50(2.78)$ & $17.48(1.94)$ & $16.75(2.32)$ & $17.09(2.40)$ \\
\hline Range (years) & $13-22$ & $13-22$ & $13-22$ & $13-22$ \\
\hline Male (female) & $17(15)$ & $9(12)$ & $28(35)$ & $54(62)$ \\
\hline Birth order (SD) & $2.13(1.13)$ & $2.19(1.08)$ & $2.03(1.09)$ & $2.08(1.09)$ \\
\hline Family size (SD) & $4.92(1.18)$ & $5.65(2.17)$ & $4.57(1.42)$ & $4.84(1.55)$ \\
\hline Maternal educational level $(\%):<12$ years $(>12$ years) & $78.12(21.88)$ & $76.19(23.81)$ & $77.78(22.22)$ & $77.59(22.41)$ \\
\hline $\begin{array}{l}\text { Family income (\%): } \\
(\leq 10,000,000 \text { IRR, } 10,000,001-30,000,000 \text { IRR, } \\
\geq 30,000,001 \text { IRR) }\end{array}$ & $(71.88,28.12,0)$ & $(76.19,23.81,0)$ & $(73.01,22.23,4.76)$ & $(73.28,24.13,2.59)$ \\
\hline
\end{tabular}

Table 2. Mean and standard deviation of subscales of family communication patterns in three groups.

\begin{tabular}{lcccccc} 
Groups & \multicolumn{2}{c}{ Individuals with B } & \multicolumn{2}{c}{ Individuals with D } & \multicolumn{2}{c}{ Individuals with TD } \\
Dependent variable & M & SD & M & SD & M & SD \\
Conversation orientation & 22.43 & 5.02 & 30.25 & 10.47 & 39.29 & 10.80 \\
\hline Conformity orientation & 24.86 & 5.77 & 24.56 & 5.51 & 19.31 & 9.27 \\
\hline
\end{tabular}

B, Blindness; D, Deafness; TD, Typical Development.

Table 3. The results of multivariate analysis of variance for family communication patterns' subscales in three groups.

\begin{tabular}{lccccc} 
Effect & Value & F & Hypothesis if & Error df \\
Group, Wilks' Lambda & 0.653 & 13.290 & 4.000 & 224.000 & 0.000 \\
\hline
\end{tabular}

Table 4. The results of multivariate analysis of variance for family communication patterns' subscales in three groups.

\begin{tabular}{lccccc} 
Variables & Sum of Squares & df & Mean Square & F & \\
Conversation orientation & 5.014 .241 & 2 & 2.507 .121 & 25.44 & 0.001 \\
Conformity orientation & 833.525 & 2 & 416.763 & 6.794 & 0.002 \\
\hline
\end{tabular}


difference between the groups' means. The results showed that there is a significant difference between the individuals with blindness and deafness, in one hand, and the individuals with typically developing, in the other hand, in terms of conversation orientation $(\mathrm{P}<.01)$. That is, conversation orientation in individuals with typically developing is higher than individuals with blindness and deafness. Furthermore, conversation orientation in individuals with blindness is significantly higher than individuals with deafness. Moreover, the results showed that there is a significant difference between the individuals with blindness and deafness, in one hand, and the individuals with typically developing, in the other hand, in terms of conformity orientation $(\mathrm{P}<.01)$. That is, conformity orientation in individuals with blindness and deafness is higher than individuals with typically developing. It is noteworthy that there is no significant difference between individuals with blindness and deafness in terms of conformity orientation $(\mathrm{P}>.05)$.

\section{Conclusions}

The aim of present study was to compare family communication patterns among Iranian individuals with blindness, deafness and individuals with typically developing. The findings showed that conversation orientation in individuals with typically developing is higher than individuals with blindness and deafness. In order to explain this finding, it can be stated that blindness and deafness can negatively affect the interpersonal relationships of family members and reduce active participation and acceptance and social performance by individuals with blindness and deafness (Wallhagen, Strawbridge, Shema, Kurata, \& Kaplan, 2001). In addition, poor social support, loneliness, lack of social networks and negative social attitudes are among the most important challenges facing people with blindness and deafness. The existence of these social challenges along with psychological challenges (such as depression, anxiety and low mental health) and functional challenges (such as the limitation of daily living skills, dependence on others and the problem of mobility and orientation) can put them in a difficult situations (Du Feu \& Fergusson, 2003) and will make conversation orientation in individuals with blindness and deafness weaker than individuals with typically developing.

Furthermore, the results showed that conversation orientation in individuals with blindness is significantly higher than individuals with deafness. In order to explain this finding, it can be stated that literatures about people with hearing impairment indicate that $59 \%$ of those with mild impairment and $80 \%$ of those with severe impairment have significant communication problems (Dalton et al., 2003). Communication problems in people with hearing impairment and weak communication and social skills in them, low willingness to engage in social interaction and not enjoy communication with others (Burkey, 2006) can be due to the weakness of the conversation orientation in individuals with deafness, while individuals with blindness have no problem in communication skills and can easily communicate with family members and others through hearing.

Moreover, the results showed that conformity orientation in individuals with blindness and deafness is higher than individuals with typically developing. For the explanation of this finding, it can be stated that the social networks of individuals with blindness and deafness are smaller compared to individuals with typically developing, and they have fewer social groups and fewer friends for social interaction and communication (Kramer, Kapteyn, Kuik,
\& Deeg, 2002). To confirm this, Azab, Kamel, and Abdelrhman (2015) concluded that individuals with blindness and deafness spend less time compared to individuals with typically developing to communicate with others. Existence of such conditions, along with limited access to social services and rejection by the community (Azab et al., 2015; Coplan, Closson, \& Arbeau, 2007) can provide a basis for the development of conformity orientation in individuals with blindness and deafness. Therefore, it can be said that for the reasons mentioned above, the conformity orientation in individuals with blindness and deafness is higher than individuals with typically developing. It is noteworthy that there is no significant difference between individuals with blindness and deafness in terms of conformity orientation. For the explanation of this finding, it can be stated that when a child is diagnosed as having a disability, the parents' expectations change for the child and her future (Boström, 2012). In other words, parental experience of their child's disability affects parenting style and their care behavior (Zeanah \& Benoit, 1995). In fact, the parents of individuals with disabilities to control and manage their child with disabilities, impose additional barriers and limitations and without any explanation, force the child to adhere to their rules and instructions or they strongly support a child with a disability, they do all their work, ignore their abnormal behaviors, and do not any control over their behavior (Billen, 2012). Both of mentioned parenting styles lead to a development of conformity orientation and increase the dependency of individuals to the family. This is probably why there is no difference between individuals with blindness and deafness in terms of conformity orientation.

Future researchers are recommended to consider the family communication patterns between individuals with blindness, deafness and individuals with typically developing in different agegroups. Also, in order to generalize the results, future researchers are advised to investigate the family communication patterns of individuals with blindness, deafness and individuals with typically developing in a larger sample in different populations. In addition, it is recommended to compare the family communication patterns of individuals with blindness and deafness to individuals with developmental disabilities (such as individuals with autism spectrum disorder, individuals with intellectual disability, etc.). It is also suggested that institutions and officials dealing with individuals with blindness and deafness, design and implement some training programs to improve family communication patterns in individuals with blindness and deafness.

Finally, it should be noted that this research has been conducted on the Iranian individuals with blindness, deafness and individuals with typically developing, so the results can only be generalized to this population. Given the age limit of the present study, which was conducted only on the age group of 13 to 22 years old, the generalization of its results to other age groups requires further research.

\section{References}

Azab, S. N., Kamel, A., \& Abdelrhman, S. S. (2015). Correlation between Anxiety Related Emotional Disorders and Language Development in Hearing-Impaired Egyptian Arabic Speaking Children. Journal of Communication Disorders, Deaf Studies \& Hearing Aids, 3, 1-6.

Behboodi Moghadam, Z., Ghiyasvandian, S., Shahbazzadegan, S., \& Shamshiri, M. (2017). Parenting experiences of mothers who are blind in Iran: A hermeneutic phenomenological study. 
Journal of Visual Impairment \& Blindness, 111(2), 113-122.

Billen, R.M. (2012). Families of young children with developmental disabilities: a model of the parenting process. Master's Thesis. Available from http://trace.tennessee.edu/cgi/viewcontent.cgi?article $=2534 \&$ context $=$ utk_gradthes

Boström, P. (2012). Experiences of parenthood and the child with an intellectual disability. Department of Psychology, University of Gothenburg, Sweden. Available from https:/gupea.ub.gu.se/bitstream/2077/31454/1/gupea_2077_3 1454 1.pdf

Burkey, J. M. (2006). Baby boomers and hearing loss: a guide to prevention and care. New Brunswick, NJ: Rutgers University Press.

Chaffee, S. H., McLeod, J. M., \& Wackman, D. B. (1973). Family communication patterns and adolescent political participation. In J. Dennis (Ed.), Socialization to Politics. New York: Wiley \& Sons. pp 349-364.

Charoenthaweesub, M., \& Hale, C. L. (2011). Thai family communication patterns: parent-adolescent communication and the well-being of Thai families. The first international conference on interdisciplinary research and development, 19(SPI), 1-6.

Clark, A. M. (2015). Family communication patterns and adolescent emotional well-being: cross classification of mother-child and father-child interactions. Doctoral dissertation. Available from: http://ir.library.oregonstate.edu/concern/graduate_thesis_or_dissertations/ht $24 \mathrm{wm} 977$

Coplan, R. J., Closson, L. M., \& Arbeau, K. A. (2007). Gender differences in the behavioral associates of loneliness and social dissatisfaction in kindergarten. Journal of Child Psychology and Psychiatry, and Allied Disciplines, 48(10), 988-995.

Dalton, D. S., Cruickshanks, K. J., Klein, B. E., Klein, R., Wiley, T. L., \& Nondahl, D. M. (2003). The impact of hearing loss on quality of life in older adults. The Gerontologist, 43(5), 661668.

Desselle, D. D., \& Pearlmutter, L. (1997). Navigating two cultures: Deaf children self-esteem and parents communication patterns. Social work in education, 19(1), 23-30.

Doostzade, M., Hemmati Alamdarloo, G., \& Shojaee, S. (2017). The effectiveness of family-centered early intervention based on psychological well-being on the general health of mothers of children with hearing impairment. Auditory and Vestibular Research, 26(3), 163-170.

Du Feu, M., \& Fergusson, K. (2003). Sensory impairment and mental health. Advances in Psychiatric Treatment, 9(2), 95103.

Durdevany, I., Moin, V., \& Yahav, R. (2007). The social life and emotional state of adolescent children of parents who are blind and sighted: a pilot study. Journal of Visual Impairment \&Blindness, 101(3), 160-171.

Farrell, A. F., \& Krahn, G. L. (2014). Family life goes on: disability in contemporary families. Family relations, 63, 1-6.

Fathizadeh, N., Takfallah, L., Badrali, N., Shiran, E., Savabi Esfahani, M., \& Akhavan, H. (2012). Experiences of blind children caregivers. Iranian Journal of Nursing \& Midwifery Research, 17(2), 143-149.

Feghhi, M., Khataminia, G., Ziaei, H., \& Latifi, M. (2009). Prevalence and causes of blindness and low vision in Khuzestan province, Iran. Journal of Ophthalmic and Vision Research, 4 (1), 29-34.

Fitzpatrick, M. A. \& Ritchie, D. L. (1994). Communication schemata within the family: Multiple perspectives on family interaction. Human Communication Research, 20(3), 275-301.

Fitzpatrick, M. A. (1988). Between husbands \& wives:
Communication in marriage. Thousand Oaks, CA, US: Sage Publications, Inc.

Golpich, Z., Darrodi, H., \& Soleimanyan, A. A. (2012). A study of the relationships between family functioning and psychological hardiness among parents with exceptional children and normal children. Iranian Rehabilitation Journal, 10(15), 56-61.

Hajloo, N., \& Ansari, S. (2011). Prevalence and causes of hearing handicap in Ardabil province, Western Iran. Audiology, 20(1), 116-127.

High, A. C., \& Scharp, K. M. (2015). Examining family communication patterns and seeking social support direct and indirect effects through ability and motivation. Human Communication Research, 41, 459-479.

Hosseinkhanzadeh, A. A., Seyed Noori, S. Z., Yeganeh, T., Esapoor, M. (2014). Comparison of siblings' relationships in families with mentally retarded, deaf and nondisabled children. Procedia - Social and Behavioral Sciences, 114, 14-18.

Khooshab, E., Jahanbin, I., Ghadakpour, S., \& Keshavarzi, S. (2016). Managing parenting stress through life skills training: A supportive intervention for mothers with visually impaired children. International Journal of Community Based Nursing and Midwifery, 4(3), 265-273.

Koerner, A. F., \& Fitzpatrick, M. A. (2002a). Understanding family communication patterns and family functioning: The roles of conversation orientation and conformity orientation. Communication Year Book, 28, 36-68.

Koerner, A. F., \& Fitzpatrick, M. A. (2002b). Toward a theory of family communication. Communication Theory, 12, 70-91.

Koerner, A. F., \& Maki, L. (2004). Family communication patterns and social support in families of origin and Aault childrens subsequent intimate relationships. Paper presented at the International Association for Relationship Research Conference; Madison, WI, 1-39.

Koerner, A. F., \& Schrodt, P. (2014). An introduction to the special issue on family communication patterns theory. Journal of Family Communication, 14(1), 1-15.

Koerner, F. A., \& Mary Anne, F. (2002). Understanding family communication patterns and family functioning: The roles of conversation orientation and conformity orientation. Annals of the International Communication Association, 26(1), 36-65.

Kramer, S. E., Kapteyn, T. S., Kuik, D. J., \& Deeg, D. J. (2002). The association of hearing impairment and chronic diseases with psychosocial health status in older age. Journal of Aging and Health, 14(1), 122-137.

Mahdieh, N., Rabbani, B., Wiley, S., Akbari, M.T., \& Zeinali, S. (2010). Genetic causes of nonsyndromic hearing loss in Iran in comparison with other populations. Journal of Human Genetics, 55(10), 639-648.

Meyer, D. J., \& Vadasy, P. (2008). Sibshops: Workshops for sibling of children with special needs (Rev. ed.). Baltimore, London: Paul H. Brooks Publishing.

Movallali, G., Abdollahzadeh rafi, M., Nemati, N. (2013). Comparison of general health status in mothers of hearing and hearing-impaired children. Audiology, 22(2), 33-39.

Pourseyyed, S., Habibollahi, S., Faramarzi, A. (2010). Effectiveness of life skills educational program on blind and low-vision university students' compatibility (Persian). Iranian Journal of Educational Strategies, 3(1), 7-11.

Ramezani, A., Pardis, M., Rafati, N., Kazemi-Moghaddam, M., Katibeh, M., Rostami, P., Dehghan, M.H., Javadi, M.A., Rabbanikhah, Z. (2012). Causes of visual impairment among patients referred to a visual rehabilitation clinic in Iran. Korean Journal of Ophthalmology, 26(2), 80-83. 
Ritchie, L. D. \& Fitzpatrick, M. A. (1990). Family communication patterns: Measuring intrapersonal perceptions of interpersonal relationships. Communication Research, 17, 523-544.

Robinson, E., \& Miller, R. (2012). Adolescents and their families: Best interests case practice model specialist practice resource. Melbourne: Victorian Government Department of Human Services.

Rousta, Z., Esfandiari Bayat, D., \& Ayyazinia, A. (2014). A comparison of family communication patterns and time management between two groups of students with either academic success or failure. Journal of Novel Applied Sciences, 3(8), 908-914.

Rubin, R. B., Rubin, A. M., Graham, E. E., Perse, E. M., \& Seibold, D. R. (2009). Communication Research Measures II: A Sourcebook. New York, NY: Routledge.

Sarabandi, A., Mobaraki, H., Chabok, K., Soltani, S. (2014). The effect of rehabilitation Services on quality of life for the blind (Persian). Modern Rehabilitation Journal, 7(4), 48-56.

Soori, H., Javadi, M. A., \& Rafati, N. (2011). Prevalence and caus- es of low vision and blindness in Tehran province, Iran. Journal of the Pakistan Medical Association, 61(6), 544-549.

Tavakol, K., Dehi, M., Naji, H., \& Nasiri, M. (2008). Parental anxiety and quality of life in children with blindness in Ababasire institution. Iranian Journal of Nursing \& Midwifery Research, 13(4), 141-144.

Wallhagen, M. I., Strawbridge, W. J., Shema, S. J., Kurata, J., \& Kaplan, G. A. (2001). Comparative impact of hearing and vision impairment on subsequent functioning. Journal of the American Geriatrics Society, 49, 1086-1092.

Yaghotian, M., Soliemanian, A., \& Darrodi, H. (2015). The effectiveness of cognitive-behavioral group therapy on selfconcept of visually impaired adolescents. Iranian Rehabilitation Journal, 13(4), 6-12.

Zeanah, C. H., \& Benoit, D. (1995). Clinical applications of a parent perception interview in infant mental health. Child and Adolescent Psychiatric Clinics of North America, 4(3), 539554. 